\title{
Universe: A Concept Analysis
}

\author{
Alma Alvarado ${ }^{1}$, Jennifer Watson ${ }^{2}$ and Sharon L. Van Sell ${ }^{*}$ \\ ${ }^{1}$ Graduate Nursing Program, Texas Woman's University, USA \\ ${ }^{2}$ Graduate Nursing Program, Texas Woman's University, USA \\ ${ }^{3}$ Professor, The Houston J. and Florence A. Doswell College of Nursing, Texas Woman's University, USA
}

\begin{abstract}
The concept of universe is a broad concept with limited analysis within nursing research and practice. The universe consists of everything that exists. The universe is all physical matter, including all the stars, planets, galaxies, and everything that exists within them such as human beings and nature. The concept analysis of theuniverse utilized the Walker and Avant eight-step methodology. The aim of the concept analysis was to provide knowledge and understanding of universe connection and interconnection in its entirety to human beings and health care, especially in advanced practice nursing. Attributes of the concept of universe include human being, environment, and cognition. Antecedents of the concept were observation, introspection, and experience. Lastly, the consequences of universe were self-awareness, evolution, and support.
\end{abstract}

\section{Introduction}

How can the concept of universe be related to advanced nursing practice? It is hard to imagine and understand how the universe can influence one's health and healthcare. The universe described as all of time and space and its contents including planets, the moon, stars, galaxies, and all matter and energy [1]. Florence Nightingale suggested that the universe "is the incarnation of a divine intelligence that regulates all things through law" (p. 8) [2].The authors' purpose was to explore and analyze the relationship and interconnection between the universe and human beings (nurse and patient) through energy fields and universal laws. By analyzing the concept of universe, the authors agreed that the universe is important to advanced practice nursing. The universe is important because it helps nursing research understand how human beings, nature, and the environment work together according to the laws of the universe and how everything on earth connects to the universe including our body, mind, and spirit. The universe in its entirety influences human beings, health, healthcare and consequently, advanced practice nursing, which assists in the understanding that everything is interconnected. The authors explored ways of how advanced practice nursing can use this connection to its advantage to provide holistic care to the patient.

\section{Aim of the Concept Analysis}

According to Walker and Avant [3], the aim or purpose is used to distinguish between the defining attributes of a concept and its irrelevant structure by breaking it into simpler elements and focusing attention on what exactly is intended to obtain from the analysis. The aim or purpose of analyzing the concept of universe is to identify the connections and interconnections between the universe and human beings and their health within their environment. "Indigenous traditions and contemporary scholars remind us that we live in a universe in which all things are connected, and in which nature continues to offer its gifts in co-creative partnership for the health and wellbeing of all" (p. 35) [4]. For the advanced practice nurse (APN), the purpose of concept analysis of universe was to provide an understanding of how to connect the patient's body, mind, and spirit to nature and ultimately to the universe as a whole in order to restore his or her energy balance and therefore, his or her health.In addition, by analyzing the concept of universe, the advanced practice nurse can be able to incorporate new methods and techniques that can be useful to provide a better holistic healthcare to the patient.

\section{Relating Theory to Practice}

Martha E. Rogers's theory of unitary human being identifies nursing as both science and art.An early education influenced Roger's abstract system in arts, a background in science, and a strong interest in space. Her nursing theory provides an approach to understanding the unitary human being, who is integral to the universe [5]. One of the concepts of Roger's nursing theory is energy field. According to Rogers, the energy field is the fundamental unit of both the living and the non-living [6]. Roger defined human being as an indivisible, pandimensional energy field identified by patterning and manifesting characteristics specific to the whole [6]. Similarly, the environment defined as irreducible, pan-dimensional energy field identified by patterning and integral with the human field [6]. Consequently, the two fields coexist and are integral to each other within the universe. Thus, human beings are energy fields integral to the environment. The principle of integrality states that the human field and the environmental field are engaged in a continuous mutual process [6]. Rogers' science also provided a natural approach to healing such as therapeutic touch, imagery, and meditation. Guided imagery, meditation, movement exercises, therapeutic touch, patterning of the environment, the use of color, and music developed as patterning techniques for the purpose of promoting a harmonious relationship between humans and the universe [6]. The "key to living human being science is viewing of the integration of humankind and the environment, which is considered to be the universe" (p. 325) [5].

\section{Definition of Universe and its uses}

The concept universe defined and used in various disciplines throughout the years. According to the Merriam-Webster Online Dictionary [1], the universe is "all of space and everything in it

"Corresponding Author: Prof. Sharon L. Van Sell, The Houston J. and Florence A. Doswell College of Nursing, 5500 Southwestern Medical Avenue, \#7209, Dallas, Texas, USA, 75235-7299, Tel: 1-864-275-3527, FAX: 214-689-6539; E-mail: svansell@twu.edu

Citation: Alvarado A, Watson J, Van Sell SL (2017) Universe: A Concept Analysis Int J Nurs Clin Pract 4: 227. doi: https://doi.org/10.15344/2394-4978/2017/227

Copyright: (c) 2017 Alvarado et al. This is an open-access article distributed under the terms of the Creative Commons Attribution License, which permits unrestricted use, distribution, and reproduction in any medium, provided the original author and source are credited. 
including stars, planets, and galaxies" (para.1). The Oxford Dictionary defined the universe as "all existing matter and space considered as a whole; the cosmos," (para. 1) [7]. Besides nursing, other disciplines that are interested in studying the complexity of the universe include Physical Cosmology, religion, paganism, and philosophy.

Physical Cosmology is the discipline that studies the universe in its totality. In addition, Cosmology is the scholarly and scientific study of the origin, evolution, structures and dynamics, scientific laws, and ultimate fate of the universe [8]. Cosmologists study the evolution and composition of the universe as a system, constructing theories that help the advanced practice nursing understand the physical lawsof the universe and integrate these laws into nursing practice.

Religious Cosmology is a way of explaining the origin and the evolution of the universe based on religious mythology. Religious cosmologies usually include a process of creation by a creator deity. According to the Catholic Encyclopedia, the nature of matter and the origin of the universe was "God's creative act" (para. 25) [9]. Pagans followed a religion that "has many gods or goddesses, considers the earth holy and does not have a central authority" (para. 1) [10].

Philosophers believe that the first sense of the definition of universe is living by nature as a whole. The Greek philosophers firmly believed that cosmic nature [the universe] is a rationally organized and wellordered system and coextensive with the will of Zeus, the impersonal God[11]. Consequently, all the events that occur within the universe fit within a coherent, well-structured scheme that is favorable. Thus, "living in agreement with nature" means conforming one's will with the sequence of events that are fated to occur in the rationally constituted universe (para. 1) [11].

\section{Attributes}

Walker and Avant [3] regard defining attributes or defining characteristics of the concept as the "heart of concept analysis" (p. 162). The purpose of this stage in the concept analysis is to underline a collection of attributes most frequently associated with the concept that distinguishes it from other similar concepts [3]. The following attributes gathered from a variety of sources related to the concept universe; they are as follows: human being, environment, and cognition.

According to the Oxford Dictionary[12],"human being is a man, woman, or child of the species Homo sapiens, distinguished from other animals by superior mental development, power of articulate speech, and upright stance," (para. 1). The concept of interconnectedness reflects that the human being and the universe connect in a powerful way [13]. Within Rogers' conceptual system, human beings are energy fields integral to the environment [6]. According to the human becoming theory, the human is coexistent while co-constituting rhythmical patterns with the universe [6]. The universe has all the elements necessary for human beings to exist and survive and eventually to integrate into society and their environment. In the Complexity Integration Nursing Theorye-book, the nurse is described as "an individual human being mapping his/ her existence through experimental works within his/herself" (p. 5) [14]. The nurse socialized through a self-development reciprocal role, which is a mutual interaction between the nurse as an individual and the patient as an individual human being. "The scientific revolution of the 21 st Century, views the human being as a collective structure or as a complex open self-organizing system" (p. 39) [14]. According to Van Sell and Kalofissudis [14], three main parts, the nous, the body, and the psyche (mind, body, spirit) create the entirety of the human being (p. 67).

Environment is defined as "the surroundings or conditions in which a person, animal, or plant lives or operates" (para. 1) [15]. The environment is crucial for the patient's health to achieve recovery. Florence Nightingale introduced the environmental theory, which focuses on taking care of the patient's environment to reach health goals and cure illness. She served as a nurse in the Crimean War where she observed a correlation between the soldiers who died and the environmental conditions. As a result, Nightingale developed the environmental theory [15]. Nightingale believed that by altering the patient's environment, could produce a change in his or her health. The environmental factors that affect health are fresh air, pure water, sufficient food supplies, efficient drainage, cleanliness of the patient and environment, and light (especially sunlight) [4]. Nature continues to offer its gift in co-creative partnership for the health and wellbeing of all. Nature is a source of nutrition and support for our whole bodymind-spirit being [4]. Thus, nature is integral to our total health.

The Merriam-Webster Online Dictionary defined the concept of cognition as "conscious mental activities, the activities of thinking, understanding, learning, and remembering" (para. 1) [17]. Cognition is a mental action that assists human beings to interact with their environment. Human beings are capable of understanding, learning and remembering what environment they feel more comfortable in and therefore, interact with the universe by understanding and experiencing life and nature.

\section{Antecedents and Consequences}

Several antecedents must be present for the concept of universe to exist. Antecedents of crucial importance include observation, introspection, and experience. Observation is one example of an important antecedent. The Complexity Integration Nursing Theory provided an example that taught individuals how to practice and master the technique of self-observation. "The Self Observation methodology incorporates the Self-Observation technique, which is comprised of the three actions of deep relaxation which incorporates introspection, self-observation, and transcendence; all occurring within a specific time and space; resulting in transcended reflection to discover balance or unbalance on the axis of nous, physical and psyche" (p. 8) [14].

Introspection and experience are also antecedents vital to the concept universe. According to the Merriam-Webster Online Dictionary[18], introspection is defined as, "the process of examining your own thoughts or feelings" (para. 1). An advanced practice nurse must first be aware of his or her unique emotions prior to effectively accounting for those of the patient. Introspection is directly related to the self-observation technique. According to Van Sell and Kalofissudis [14], "The Self-observation technique requires the nurse to learn deep relaxation with introspection, Self-observation, and transcendence, all occurring within a specific space and time" (p. 85).

Experience is related to both the nurse and the patient. Each individual will convey a unique level of experience. For example, a prior hospitalization experience will affect a patient's perception of care. Whereas, a nurse's level of experience will contribute to the delivery and performance of care. Consequences result from the 
concept universe and include self-awareness, evolution, and support. "The development of self-awareness as a strategy to succeed in the CNS role is affected largely by the practice of reflection" (p. 147) [19]. Mastery of self-awareness will permit the nurse to rapidly recognize appropriate emotions and direct those feelings toward positive avenues of action.

As the concept of universe is applied, evolution is a critical consequence. Evolution can occur for both the nurse and the patient. In conjunction within the realm of evolving healthcare and mastery of self-observation, the APN can provide individualistic best practice for patients. Judy Murphy [20] supported this phenomenon by what she termed, "...patient centric care view, where the patient actively participates in his or her care, and we look at delivering care from a patient's point of view" (p. 35). Evolution in the delivery of healthcare occurs as a result of recognizing a patient's unique universe and directing care to foster that realm. "When care is centered around the patient, opportunity exists to remove unneeded and unwanted services" (p. 36) [20].

The consequence of support stems from the realization of the individual's entire universe. As a result, all of the factors that comprise the patient's universe are considered and ideally incorporated into the direction of healthcare.

\section{Model Case}

The model case is an example of the use of the concept that includes all the critical attributes of the concept [3]. A great example of a model case is a sea captain, who displays the attributes of human being, environment, and cognition. A sea captain with severe sepsis was in ICU for a long period and expressed no hope of recovery. The ICU nurse using the self-observation method took the patient with all his IV's, central catheter, and drainage systems out of the ICU to a balcony facing the sea for the sea captain to reconnect with his normal environment, which resulted in the patient gaining hope of recovery [14].

The sea captain demonstrates all the defining attributes of the concept universe. The sea captain being a human being used his cognition to understand and perceived what type of environment he was in when the nurse took him close to the sea. He as a human being connected himself to nature and the environment that he had experienced before and interconnected with the universe. Consequently, the sea captain gained hope for recovery.

\section{Borderline Case}

A borderline case is one in which some, but not all of the attributes are present[3]. In the proceeding example, presented is a scenario representing a borderline case for the concept universe.

Michelle is a registered nurse with ten years of experience in her area of expertise. She has practiced self-observation techniques and considered herself to be fully cognizant of her role within her own environment. However, she has not yet realized her place in the universe of her patients. She was more aware of her presence and her function within her individual realm. She saw herself as compassionate and eager to assist patients in obtaining a level of healing. However, her patient needed her to be more aware of their unique universe. She hasn't mastered the self-observation technique and therefore doesn't have the full awareness of the environment.
Michelle's assignment was to a 68-year-old male patient diagnosed with pneumonia who was depressed after having lost his wife two years ago to breast cancer. Michelle felt she demonstrated sufficient compassionate care since she treated the patient with appropriate medications. Unfortunately, she failed to seek and include the patient regarding alternative treatment options and personal preferences. She neglected to engage the patient in assessing the simple things that could assist the patient to heal or even to foster a restoration of hope.

In her opinion, medication was the best treatment and only necessary intervention to restore her patient to a state of wellbeing and ultimately discharge from the hospital. The patient did not respond well to medication alone and became more agitated with Michelle. Had she taken the time to engage in effective selfobservation with introspection, she would not hesitate to recognize disconnect within her patient's universe. Consequently, the patient felt most comfortable cuddled up with his favorite blanket from home and most connected to nature by keeping an Echinacea plant at the bedside. Michelle disregarded the opportunity to seek out such simple interventions.

Nurse Michelle was able to employ some of the attributes of the concept universe as demonstrated in the borderline case. She was cognizant of her universe and environment. She failed to consider entering the patient's universe to be fully present in assisting his return to health. She missed an opportunity to become an integral component of the patient's universe and thus remained distant and uninvolved. Futility ensued when failure to fully engage within another individual's universe existed.

\section{Contrary Case}

A contrary case is one in which none of the attributes of the concept are present [3]. Rachel frequently fought with her live-in boyfriend, and she has been contemplating moving out. She felt mentally and emotionally distracted. When she arrived at work, she wiped her tears away and sulked into her shift. A 19-year-old presented to the emergency department (ED) with signs and symptoms of strep. Nurse Rachel was personally frustrated and emotionally exhausted.

She wished to get through her shift as quickly as possible. She halfheartedly assessed the patient and before obtaining a full assessment had mentally decided he must have strep. She treated the patient in such a manner. She ignored all other information provided by patient and family. The patient was scared and reiterated he just didn't feel right. He had strep many times as a child, but this felt different. Nurse Rachel in a hurried state recommended the patient rest and take prescribed medications. She dismissed the patient without another thought. Later that evening, the family returned to the ED and the patient could no longer walk. His health had declined quickly and aggressively. The patient receiveda diagnosis of bacterial meningitis.

Nurse Rachel never bothered to engage in self-observation. Had she done so, she would have opened herself up to entering the patient's universe. She would have had listened to the family and the patient when he knew something felt very different. The patient's support system is an integral component of their universe.

\section{Empirical Referents}

According to Walker and Avant [3] "Determining the empirical 
referents for the defining attributes is the final step in a concept analysis" (p. 168). A defining attribute for the concept of universe would be cognition, and an empirical referent would include selfawareness. APNs must be aware of the skill self-awareness to incorporate the modality into current nursing practice effectively. In a column by, De Natale and Klevay [21], "Parse's theory of human becoming and the associated teaching-learning processes were used as underpinnings to guide students as they come to know more about themselves and others" (p. 125). Self-awareness is a skill that ought to be taught at the nursing student level and honed throughout an entire career. De Natale and Klevay [21] further explained:

The teaching-learning processes help nursing students understand that being present and bearing witness are an important part of honoring quality of life and respective value choices. The purpose of this column is to highlight the human becoming teaching-learning processes as students explore their experiences of learning to be with other in true presence [21, p. 125].

\section{Impact of the Concept of Universe}

The concept of universe extends across a vast area of the advanced nursing practice role. APNs can recognize and provide individualistic interventions based on the concept of universe as applied to the patient's entirety. With apriority on the interconnectedness of the patient's universe, healthcare interventions can be most efficient. The APN can render herself or himself to being truly and actively present with the patient. Conjunctively the two can work in tandem to achieve a positive restoration. The concept of universe has significance within the nursing research field as research will directly affect practice.

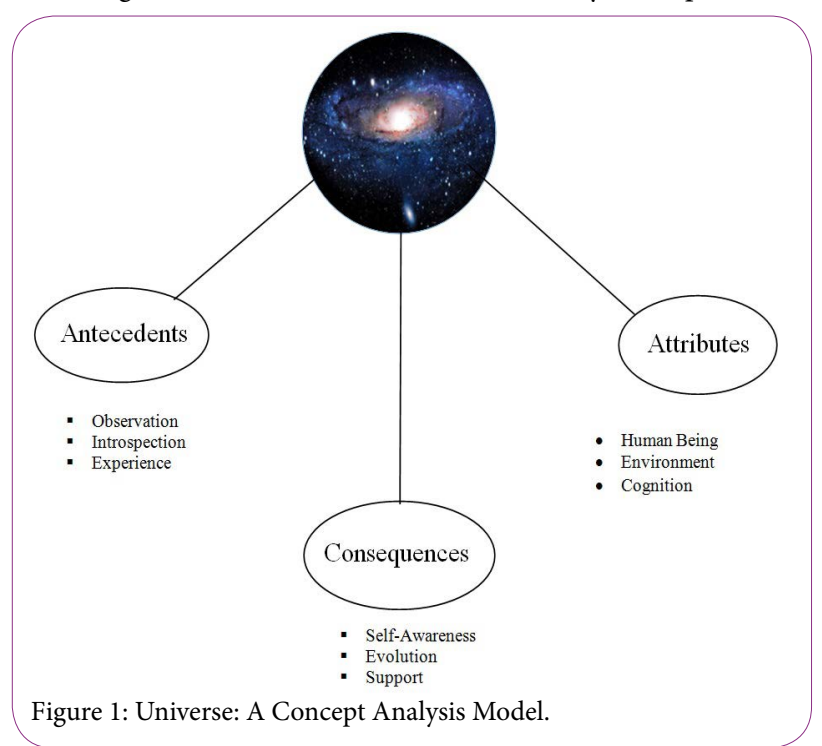

\section{Discussion}

Figure 1 displays a model of universe analyzed using the concept analysis method to describe the complexity of the universe better. The model shows the attributes, antecedents, and consequences of the concept of universe. The attributes are human being, environment, and cognition. The antecedents include observation, introspection, and experience. Finally, the consequences are as follow, self-awareness, evolution, and support. The concept of universe is a complex concept and sometimes hard to connect to the human beings. However, by understanding the concept of universe in the advanced practice nursing, nurses can interconnect patients with the universe and therefore provide a holistic nursing care, which has the aim of healing the whole person.

\section{Competing Interests}

The authors declares that the they have no competing interests.

\section{Funding}

This article was published with support from Texas Woman's University Libraries' Open Access Fund.

\section{References}

1. Universe (2015) In Merriam-Webster online dictionary.

2. Macrae J (1995) Nightingale's spiritual philosophy and its significance for modern nursing. Image: Image J Nurs Sch 27: 8-10.

3. Walker LO, Avant KC (2011) Concept Analysis. Strategies for Theory Construction in Nursing (pp. 157-179). Upper Saddle River, NJ: Pearson.

4. Burkhardt MA (2000) Healing Relationships With Nature. Complementary Ther Nurs Midwifery 6: 35-40.

5. Baumann SL, Wright SG, Settecase-Wu C (2014) A Science of Unitary Human Beings' p Perspective of Global Health Nursing. Nurs Sci Q 27: 324-328.

6. Butcher HK, Forchuk C (1992) The Overview Effect: The Impact of Space Exploration on the Evolution of Nursing Science. Nurs Sci Q 5: 118.

7. Universe (2016) In Oxford Online Dictionary.

8. Physics and Cosmology (2016) In Internet Encyclopedia of Philosophy.

9. Metaphysics (2016) In Catholic Encyclopedia.

10. Paganism (2015) In Merriam-Webster's online dictionary.

11. Universe (2016) In Internet Encyclopedia of Philosophy.

12. Human being (2016) In Oxford online dictionary.

13. Love KL (2008) Interconnectedness in Nursing: A Concept Analysis. J Holistic Nurs 26: 255-265.

14. Van Sell SL, Kalofissudis IA (2002) The Evolving Essence of the Science of Nursing: Complexity Integration Nursing Theory (E-book). Athens, Greece: ICU Web Journal.

15. Environment (2016) In Oxford online dictionary.

16. Dossey B (2005) Florence Nightingale and Holistic Nursing. Imprint 52: 58.

17. Cognition (2015) In Merriam-Webster online dictionary.

18. Introspection (2016) In Merriam-Webster online dictionary.

19. Kozub E, Brown L, Ecoff L (2016) Strategies for Success: Cultivating Emotional Competence in the Clinical Nurse Specialist Role. AACN Adv Crit Care 27: 145-151.

20. Murphy $\mathrm{J}$ (2011) Patient as Center of the Health Care Universe: A closer look at patient-centered care. Nurs Econ 29: 35-37.

21. De Natale ML \& Klevay AM (2013) The Human Becoming Connection: Nursing Students find meaning in the teaching-learning process. Nurs Sci Q 26: 125-129. 